\title{
Product design based teaching reform
}

\author{
Xu Chen \\ School of Art and Design, Guilin University of Electronic Technology, Guilin 541004, China \\ chenxu1968@gmail.com
}

Keywords: Foundation design, Morphology and semantics, Transition and connection

Abstract. Purpose product base design should focus on teaching students observation skills, analytical skills and ability to think through the training system, so that students master the basic modeling capabilities and a variety of expression methods for the future of the professional courses of study as well as the creation and lay a solid basis.

\section{Introduction}

Product design is a relatively free basis of creativity, you can go to create, such as functions, color, material, texture, structure, shape, etc. for a local thing or a thing. Product design is the basis for the creation of spontaneous freedom from the preparation phase to a professionally designed, it is a transition. It is purposeful, systematic training of students ability to observe, physical modeling capability-based design skills for future professional designers to prepare. Through training to improve their hand-eye coordination skills and ability between the brain; students ability to observe, thinking ability; train their divergent thinking, creative thinking and unconventional capabilities.

\section{Products based design features:}

(1) "Useless" basic design. Product design is not the purpose of the foundation to achieve the product's features, it is the basic training on a particular aspect of product design functions involved, structures, materials, shape, etc., it is this "useless" on the surface, useful for future design basis;

(2) "No" basic design constraints. Because the basic design is the product to give up part of limiting factors, conditional defined design. Design quality is not associated with the actual needs, but defined conditions are met, and to be innovative and break under defined conditions limit;

(3) "Strange" basic design. Basic Design of Products subject and defining the conditions and requirements often far from life in general;

(4) "Original" basic design. Mankind from the original to maturity; from simple to complex; from natural to man-made; must ultimately reverting to simplicity, back to the original;

(5) Focus on basic design process.

Based on the basis of the above product design and features purpose of teaching, training content of the course as follows:

\section{Basic Design of Products training content}

3.1 Conversion from 2D to 3D

Job one: from 2D to 3D conversion exercises to a plane or a set of abstract graphic, after projection transformation into a set of three-dimensional form.

Evaluation points: (1) the same plane projection; (2) novel three-dimensional shape, creative; (3) transition from 2D to 3D and natural transition.

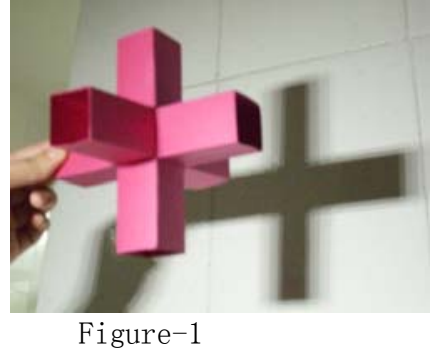

Figure-1

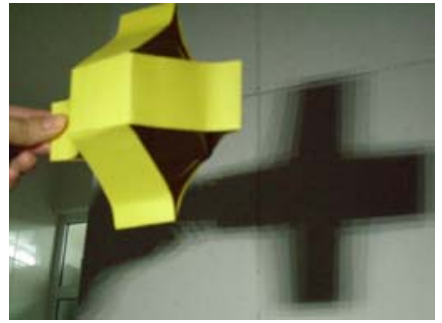

Figure-2

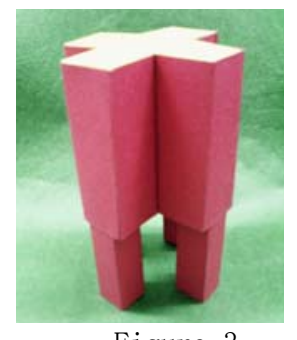

Figure-3 


\subsection{Form of transition and convergence}

Transition: one human need, through some form of transitional things linked. Things need to convert the transition, the transition will not be sudden, it will feel natural and smooth, there will be mental disorders, it is easy to accept. Coupling body is the same between two different bodies will also need to transition, including building products, furniture and other things in the traditional emphasis on its very start transforms. ${ }^{1]}$

Job 2: Select two or more materials, in the form of a spatial structure to express the relationship between morphological transition in body mass, material, structure, contrast, and coordination.

Evaluation points: (1) demonstrating contrast material, structure, shape, coordination and other relations; (2) design expression in place, the production of fine; (3) form new, creative, natural transition, but also unexpectedly reasonable. (As shown in Figure -5)

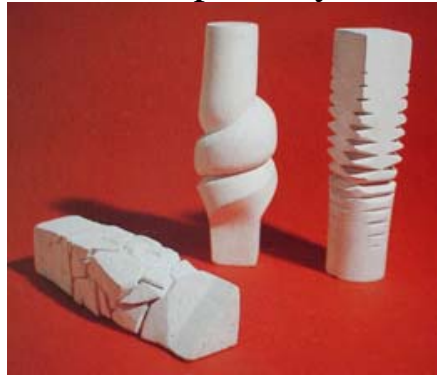

Figure-4

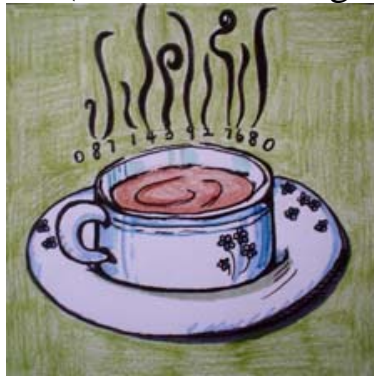

Figure -5

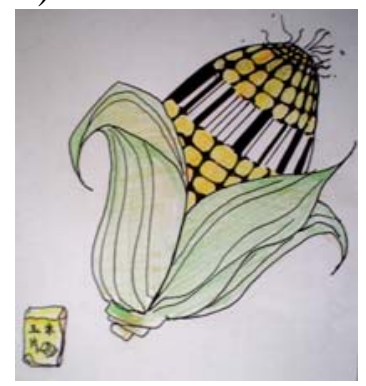

Figure-6

\section{3 morphology and semantics}

Semantics can be conveyed through the plane symbol, color, texture, shape. The main function of the symbol - will experience formalized through this form will experience objectively presented for reference to people, knowledge and understanding. - famous American media scholar Wilbur Schramm clearly stated:. "Although non-verbal symbol system is not easy to accurately compiled language, but it is through a variety of information they transmit to us" This shows that as a non-verbal design symbol image one has different language-independent function and role. ${ }^{[2]}$

\subsubsection{AC function}

And language compared to shape better than or different from the language passed in some sense deliver quality aspects. Exchange functional morphology mainly in five areas:

(1) expression Terseness. As traditional information dissemination in the flames, signal tree, modern traffic signs are the expression of information in concise manner, makes clear.

(2) Expression of rich content. In the design form, there are some people long-term use, the convention design patterns, such as the cross, national flag, national emblem, the Red Cross, gossip symbols, meaning they produce complex can not express with words in a particular environment of use.

(3) description ability. Form and language are functionally similar, and sometimes higher than the ability to form description language. If a child's literacy pictures is to make use of the graphic form of understanding the text.

(4) indirect expression of reasoning and judgment. Through concise graphical form and composition of the meaning of the expression, and let the audience make quick judgments, such as modern society is the public identification of international languages.

(5) Functions of Body Language. Body language may be accompanied by either Form design appears to supplement, modify the language, can also appear alone or inconvenience to all kinds of information can not be expressed with language expression. Such as: sign language, embrace, expression and other body language.

3.3.2 Expression Function

Expression of functional morphology mainly manifested in two aspects:

(1) illustrates the concept of function

A, for easy interpretation. People generally do not need to understand form that takes a long time, like learning languages. 
B, product semantics in favor of modern communication. Because many high-technology applications, resulting in the use of modern products on the complexity of the illustrated functional morphology can help people overcome the cumbersome exchange of text and a variety of language barriers.

C, auxiliary memory. We can form abstract concepts to vivid images to express, to deepen people's understanding of the concept and memory.

(2) performance universal emotional function

A, can be passed directly shape attitudes, emotions and feelings, and sign language difficult to do. Although fiction, poetry can also express attitudes, emotions and feelings, but it takes the reader to a language specific image conversion process in mind. ${ }^{[3]}$

$\mathrm{B}$, form is a form of symbolic system, is an expression of universal human emotion visual imagery. Universal human emotion refers to human nature, Love, love, beauty, etc., is a form of human attitudes, emotions, feelings into a visible form means. Such as sound, mood, and visual performance is the use of shape, color and other performance.

\subsubsection{Useful Features}

(1) depict sexual function. Characterized by realistic objective that imitate or form, must be certain objective characteristics of the object is the same, that is expressed on the basis of objective similarity between objects, such as orange for oranges taste of orange, outline a representative of the head of a person, and so on. In it has intuitive perception, by a similar image can be identified.

(2) indicative function. Form and objective that have a causal link between space and time or, including public information signs, such as signs, road signs indicating the road sign, the door is a building exit indicator etc. This relationship between the form and the objective is not to imitate the object, but rather indicative, and experience related.

(3) symbolic function. It does not have the shape between the object and the objective similarity or direct sexual contact, merely the result of the convention. Objective meaning about objects and forms the referent, not personal feelings generated by the association, but due to social customs, such as red symbolizes life, dove symbol of peace, in the eyes of Chinese people is a symbol of longevity and other peaches.

Form is the designer's thoughts and feelings symbols, information symbols can be expressed whether accurate, rapid and effective acceptance and understanding, it would be a sign of the success of the design work. This is the designer of the graphic symbol selection in the thinking process of the design, composition, transformation, accurately and effectively grasp the degree of regeneration of the decision. It can be said that the symbol is a tool for expressing thoughts and feelings.

As shown in Figure -5 Figure -6, The same symbol "bar code" also implies different semantics.

Third assignment: a different visual language intended to express the same theme. Such as "love books" as the theme, you can use a lot of visual language to express.

Evaluation points: (1) semantic expression vivid, accurately reflects the theme; (2) diverse performance practices; (3) form novel and creative. ${ }^{[4]}$

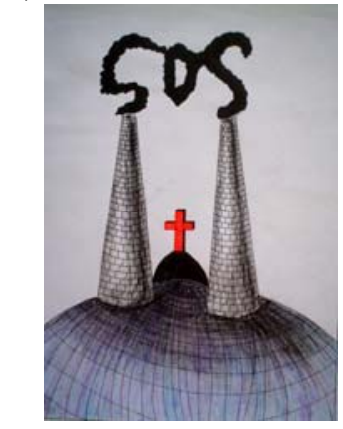

Figure-7

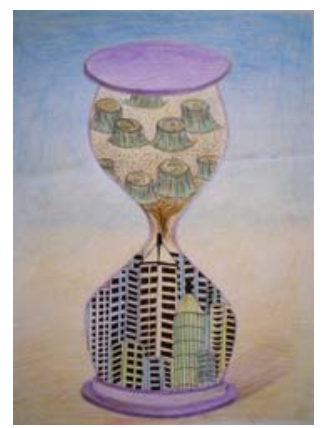

Figure-8

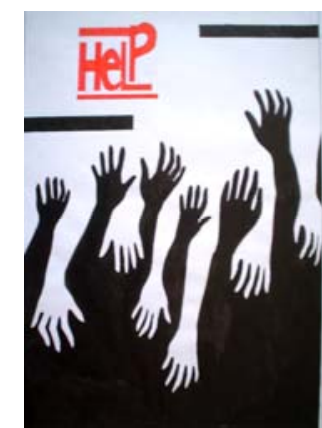

Figure-9

As shown in Figure -7-9, visual language is the expression of a variety of "green" as the theme through this exercise can be designed so that students master the semantic representation, a subject can be done from different aspects thought and expression broaden the students 'knowledge, to 
stimulate the students' creativity, but also to enable students to more actively take the initiative to think.

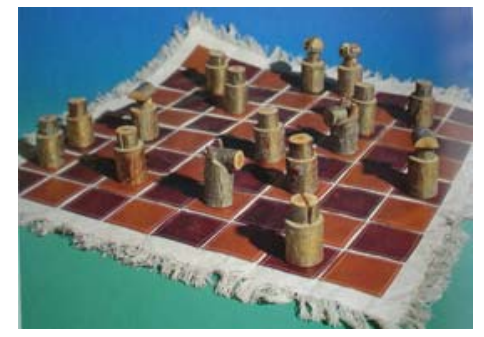

Figure-10

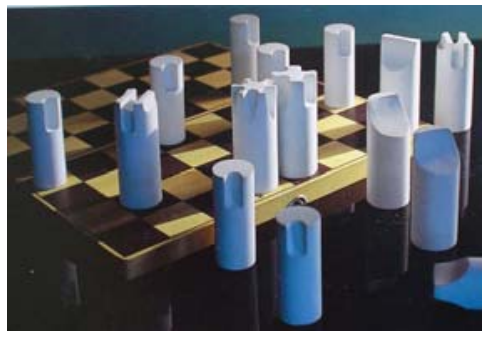

Figure-11

As shown in Figure -10 Figure -11 is made of different materials, different chess piece design modeling is completed, the students communicated through different semantic form certain purpose, to develop students skills.

\section{Summary}

By teaching these elements can enhance students' grasp constitute comprehensive thinking ability and other elements of various forms, from "flat" to "three-dimensional" form a whole, continuous and progressive teaching content and mode, so that students recognize capacity and performance ability systematic, learn to observe and analyze problems and to think, to have more performance ways to avoid blindness, and thus the future of professional courses and the creation of a solid foundation.

\section{Acknowledgement}

This study is the outcome of 2016 strong base in Guangxi region of excellence projects.

\section{References}

[1] Alex Ng • White [US] HUANG Wen, Wu literature (translation) Graphic Design principle [M]. Shanghai: Shanghai People's Fine Arts Publishing House .2005.1

[2] Hu Mingzhe forms multiply [M] Beijing: People's Fine Arts Publishing House .2004.6

[3] Zhou Zhiyu transition - from natural form to the abstract form [M]. Changsha: Hunan Fine Arts Publishing House .2000.6

[4] Chen $\mathrm{Xu}$ design course in Teaching Reform [M] International Industrial Design Seminar Proceedings, P187-190 Beijing: Mechanical Industry Press .2001.10

[5] Chen xu. Practice and thinking of the reform in education of art and design[C]//Proceedings of the 2008 International Conference on Industrial Design, 2008: 372-375. 